\title{
Biochemical Significance of Soluble Endoglin as a Possible Marker Predicting Cardiovascular Diseases in obese and obese Type 2 Diabetic Patients
}

\author{
Azza A. Atef ${ }^{* 1}$, Magda K. Ezz ${ }^{1}$, Mohamed M. Badran ${ }^{2}$ and Ibrahim A. Emara ${ }^{3}$ \\ ${ }^{1}$ Department of Biochemistry, Faculty of Science, Ain Shams University, Cairo, Egypt, \\ ${ }^{2}$ Institute of Scientific Research and Revival Islamic Heritage, Umm Al-Qura University, Makkah, Kingdom of Saudi \\ Arabia (KSA), \\ ${ }^{3}$ Biochemistry Department, National Institute of Diabetes and Endocrinology, Cairo, Egypt
}

ARTICLE INFO

Article history:

Received 29 April 2014

Accepted 03 June 2014

Keywords:

Soluble endoglin;

type 2 diabetes;

obesity;

endothelial dysfunction;

oxidative stress.

\begin{abstract}
A B S T R A C T
Obesity-associated insulin resistance is a major risk factor for Type 2 diabetes and cardiovascular diseases. Endoglin is co-receptor for members of the transforming growth factor (TGF)-superfamily and is highly expressed on vascular endothelial cells. The objective is to examine endoglin as a possible marker predicting cardiovascular complications in obese subjects with or without type 2 diabetes mellitus (type $2 \mathrm{DM}$ ). Four groups (22 subjects each) were included: normal control, obese without type $2 \mathrm{DM}$, non-obese type $2 \mathrm{DM}$ and obese with type $2 \mathrm{DM}$. Plasma glucose, insulin, glycosylated hemoglobin (HbA1c) levels and homeostasis model assessment of insulin resistance (HOMAIR) were significantly elevated $(P<0.05)$ in both groups of type $2 \mathrm{DM}$ as compared to the control group indicating poor glycemic control. Unfavorable serum lipids patterns were dramatically found in the obese and obese DM patients than the control and type 2 diabetic groups respectively. The significant increase in serum malondialdehyde (MDA) and the significant decrease $(P<0.05)$ in the total antioxidant capacity (TAC) levels were observed in all groups compared to the control group, however, with higher $\%$ change values in the obese type $2 \mathrm{DM}$ group (48.22 and -48.71 respectively) showing that oxidative stress is severely affected by obesity. Soluble endoglin levels were significantly higher $(P<0.05)$ in sera of obese subjects than those of control ones and in obese DM patients than in non-obese DM patients and these elevations were parallel to that of serumVCAM-1 suggesting different degrees of endothelial dysfunctions. Soluble endoglin was significantly correlated in the non-obese and obese type $2 \mathrm{DM}$ with plasma glucose $\left(r_{=}=0.542,0.652\right.$ respectively $)$, insulin $\left(r_{=} 0.589,0.682\right.$ respectively) and HOMA-IR ( $\mathrm{r}_{=} 0.517,0.551$ respectively); also with total cholesterol in the obese non type $2 \mathrm{DM}$ and obese type $2 \mathrm{DM}$ groups $(\mathrm{r}=0.446,0.459$ respectively) and with $\operatorname{MDA}\left(\mathrm{r}_{=}=0.921\right)$ in the obese diabetic group. This indicates the association between sol. endoglin with poor glycemic control, impaired lipid metabolism and oxidative stress in these groups. Therefore, soluble endoglin may suggest to be used a useful marker in the early detection of the risk of cardiovascular complications in obese and obese type 2 diabetic patients.
\end{abstract}

\section{Introduction}

Rates of diabetes have increased markedly over the last 50 years in parallel with obesity. Vascular disease is the main cause for disability and death in patients with diabetes mellitus ${ }^{[1]}$.

\footnotetext{
* Corresponding author.

E-mail address: azza_atef@hotmail.com
}

Endothelial dysfunction indicated by impaired endothelium dependent vasodilatation is common in early and otherwise uncomplicated type 2 diabetes ${ }^{[2]}$ and has also been shown to be predictive of future adverse cardiovascular events which are partly due to the frequent association of the disease with other cardiovascular risk factors, including hypertension, obesity and dyslipidemia ${ }^{[3]}$. 
Circulating biomarkers have been important in predicting development of diabetes and its complications as well as providing targets for therapy ${ }^{[4]}$. Endoglin (also known as CD105) is a type I transmembrane glycoprotein that may have roles in hematopoiesis, cardiovascular development and angiogenesis. The glycoprotein consists of a homodimer of $180 \mathrm{kDA}$ with disulfide links ${ }^{[5]}$. There are two isoforms of endoglin created by alternative splicing: the long isoform (L-endoglin) and the short isoform (Sendoglin) ${ }^{[6]}$. A soluble form of endoglin can be produced by the proteolytic cleaving action of metalloproteinase MMP-14 in the extracellular domain near the membrane ${ }^{[7]}$.

Endoglin has been shown to interact with TGF- $\beta$ receptor 3 and TGF- $\beta$ receptor 1 . It is highly expressed on vascular endothelial cells. Endoglin and activin like kinase-1 (ALK-1) proteins are specific endothelial receptors of the transforming growth factor- $\beta$ (TGF- $\beta$ ) superfamily that are essential for vascular integrity ${ }^{[8]}$. Through binding to the TGF- $\beta$ type II receptor, TGF- $\beta$ can activate two distinct type I receptors (ALK1 and ALK5) in endothelial cells, each one leading to opposite effects on endothelial cell proliferation and migration ${ }^{[9]}$. Endoglin plays a pivotal role in the balance of ALK1 and ALK5 signaling to regulate endothelial cell proliferation in response to TGF- $\beta{ }^{[10]}$. Endoglin expression was demonstrated in atherosclerotic vessels predominantly in endothelial cells and smooth muscle cells in various types of blood vessels in mice and humans, suggesting its participation on atherogenesis ${ }^{[11]}$.

Supporting the link between endoglin and metabolism is the relationship between plasma levels of endoglin and glycemia that was recently found in diabetic hypertensive patients ${ }^{[12]}$. In addition soluble endoglin (sol. endoglin) are released under hypoxic stress and is an indicator of hypertension- and diabetes-associated vascular pathologies in humans and animals ${ }^{[13,14]}$ and there is a clear association between endothelial dysfunction and alterations in glucose metabolism or metabolic syndrome ${ }^{[15]}$.

Accordingly, the present study aimed to assist the relationship between sol. endoglin and hyperglycemia, oxidative stress and endothelial dysfunction in obese and/or Type 2 diabetic patients and to evaluate whether sol. endoglin can be used as a possible biomarker predicting future adverse cardiovascular events in those patients.

\section{Subjects and Methods \\ Subjects:}

This study included 88 volunteers of both sexes (closely sex-matched by ratio in each subject group) and aged from 45 to 65 years. The participants presented as 44 non type $2 \mathrm{DM}$ subjects and 44 age matched subjects diagnosed as type $2 \mathrm{DM}$ patients (recent onset $<5$ years) according to Report of the Expert Committee on the Diagnosis and classification of Diabetes Mellitus (2006)
The participants were selected from the outpatient's clinic of National Institute of Diabetes and Endocrinology (NIDE), Cairo, Egypt. The participants in the diabetic groups were treated with oral hypoglycemic agents only. Hypoglycemic medications were withheld on the morning of the study.

Design and study populations: Subjects included in this study were further classified into the followings: 22 normal control non obese subjects (BMI $<30 \mathrm{~kg} / \mathrm{m}^{2}$ ), 22 obese subjects without type $2 \mathrm{DM}$ (BMI $\geq 30 \mathrm{~kg} / \mathrm{m} 2)$, 22 non obese type $2 \mathrm{DM}$ patients and 22 obese type 2 DM patients $\left(\mathrm{BMI} \geq 30 \mathrm{~kg} / \mathrm{m}^{2}\right)$.

Exclusion Criteria: Patients with type 2 DM complications such as diabetic nephropathy, neuropathy, retinopathy, hypertension, and heart disease based on clinical and laboratory investigations were excluded from the study. The patients were instructed not to engage in any vigorous exercise for at least 3days before the study. Each subject included in the study signed an informed consent form to participate in the study after full explanation of the purpose and nature of all procedures used. Approval was taken from the research committee of General Organization of teaching Hospitals and Institutions.

\section{Methods:}

Blood sampling: A total of $9 \mathrm{ml}$ of venous blood obtained were collected by venous puncture from each subject after 12 hours overnight fasting processed as follows: $5 \mathrm{ml}$ were subdivided into tubes with or without anticoagulant for separation of plasma and serum samples respectively, $2 \mathrm{ml}$ were added in tube with EDTA without centrifugation (whole blood sample) for assaying $\mathrm{HbA} 1 \mathrm{c} \%$ and another $2 \mathrm{ml}$ of blood samples were added in tubes with potassium oxalate and sodium fluoride for assaying of glucose.

\section{Biochemical analysis}

Diabetic biomarkers: Plasma glucose concentration was assayed by glucose oxidase method according to Trinder ${ }^{[16]}$. Blood HbA1c \% was measured according to the method of Grey et al. [17] using an immunoturbidimetric assay on Dimension RxL Max (Dade Behring). Plasma insulin was determined using human commercially available enzyme-linked immunosorbent assay kits (Bio Source Europe S.A., Nivelles, Belgium) according to Flier et al. ${ }^{[18]}$. Insulin resistance was measured using homeostasis model assessment of insulin resistance (HOMA-IR) by multiplying fasting plasma glucose $(\mathrm{mmol} / \mathrm{L})$ and fasting plasma insulin (mU/L) divided by $22.5^{[19]}$.

Lipid profile and oxidative status parameters: Commercial kits based on different techniques, purchased from Bio Med, Egy-Chem were used for the determinations of serum total cholesterol ${ }^{[20]}$, HDL-C ${ }^{[21]}$ and triglycerides ${ }^{[22]}$. Serum LDL-C was calculated as follows: LDL-C $=\mathrm{TC}-\mathrm{HDL}-\mathrm{C} / \mathrm{TG} / 5^{[23]}$ while, atherogenic index was calculated from ratio of TC/HDL-C ${ }^{[24]}$. 
Oxidative status markers: Malondialdehyde (MDA) was determined in serum as an index of lipid peroxidation according to the method described by Uchiyama and Mihara ${ }^{[25]}$ while total antioxidant capacity (TAC) was determined according to Koracevic et al. ${ }^{[26]}$ method.

Endothelial function parameters: Serum VCAM-1 was determined using quantitative sandwich enzyme immunoassay technique (Human) designed by CloudClone Corp. (USA) Catalogue: SEA547Hu. Soluble endoglin was assayed by ELISA technique provided by Human Endoglin (ENG) Kit CATALOG \#: 95702. Glory Science Co., Ltd USA, according to the method of Abdalla et al. ${ }^{[27]}$.

Statistical analysis: All results were expressed as the mean \pm SD. Statistical analysis was performed with Statistical Package for the Social Science for Windows (SPSS, version 16.0, Chicago, IL, USA). The data were analyzed by one-way analysis of variance (ANOVA). Pearson's correlation analysis was used to determine the correlation among the parameters assessed. The $P$ value less than 0.05 were considered statistically significant.

\section{Results}

Demographic characteristics of the patients and controls are presented in Table (1): No statistical differences were found between all groups with respect to age and blood pressure. However, BMI showed significant increase $(P<0.05)$ in obese group against the control group and in obese type 2 DM group against the nonobese type 2 DM group.
Diabetic biomarkers of all groups presented in Table (2): Obese subjects exhibited significant elevations $(P<0.05)$ in plasma insulin and HOMA-IR values compared to the normal non obese control group (\% change: 44.07 and $54.09 \%$ respectively).Group of patients diagnosed as type 2 DM showed significant elevations $(P<0.05)$ in plasma glucose, HbA1c \%, plasma insulin and HOMAIR levels as compared to the control group with \% changes: $133.40,68.53,52.54$ and $252.27 \%$ respectively. Obese type $2 \mathrm{DM}$ patients as compared to the non-obese diabetic ones, exhibited significant increases $(P<0.05)$ in plasma glucose levels (41.73\%), HbA1c (22.54\%) and HOMA-IR levels $(56.13 \%)$

Table (3) demonstrated the lipid profile pattern in all groups: In obese group of patients there were significant elevations $(P<0.05)$ in serum TC, LDL-C, TG levels and TC/HDL ratio while HDL-C showed significant reduction $(P<0.05)$ compared to normal non obese controls (\% changes: $29.81,21.95,149.58,41.35$ and 15.19 respectively). Non obese type $2 \mathrm{DM}$ patients exhibited significant increases $(P<0.05)$ in the levels of serum TC, LDL-C, TG, TC/HDL ratio and a significant decrease $(P<0.05)$ in HDL-C levels as compared to the normal control ones with \% changes: 26.31, 38.03, $77.95,48.65$ and $-15.42 \%$ respectively. Obese type 2 DM group of patients had significantly higher $(P<0.05)$ levels of serum TC, LDL-C, TG and TC/HDL ratio (\% changes: $28.06,40.22,40.81$ and $58.18 \%$ respectively) while they had significantly lower $(P<0.05)$ HDL-C levels $(-20.14 \%)$ than the non-obese type 2 DM group.

Table 1: Age, BMI, systolic and diastolic blood pressure of participants included in the different studied groups.

\begin{tabular}{|c|c|c|c|c|}
\hline $\begin{array}{c}\text { Parameter } \\
\text { Groups }\end{array}$ & $\begin{array}{c}\text { Age } \\
(\text { Years })\end{array}$ & $\begin{array}{c}\text { BMI } \\
\left(\mathbf{k g} / \mathbf{m}^{\mathbf{2}}\right)\end{array}$ & $\begin{array}{c}\text { SBP } \\
(\mathbf{m m ~ H g})\end{array}$ & $\begin{array}{c}\text { DBP } \\
(\mathbf{m m} \text { Hg) }\end{array}$ \\
\hline Normal Control & $52.69 \pm 11.08$ & $27.55 \pm 1.80$ & $124.00 \pm 23.00$ & $78.00 \pm 14.00$ \\
\hline Obese without DM & $53.90 \pm 11.68$ & $34.19 \pm 2.40^{\mathrm{a}}$ & $135.00 \pm 15.00$ & $85.00 \pm 10.00$ \\
$* \%$ change & 1.10 & 24.10 & 8.80 & 8.97 \\
\hline Non obese T2 DM & $55.27 \pm 12.74$ & $27.64 \pm 1.40^{\mathrm{b}}$ & $136.00 \pm 11.00$ & $85.00 \pm 8.00$ \\
$* \%$ change & 4.89 & 0.32 & 9.70 & 8.97 \\
\hline Obese with T2 DM & $60.17 \pm 14.03$ & $33.70 \pm 1.50^{\text {ac }}$ & $139.00 \pm 17.00$ & $90.00 \pm 9.00$ \\
$* \%$ change & 14.19 & 22.32 & 12.09 & 15.38 \\
$* *$ change & 8.87 & 21.92 & 2.20 & 5.88 \\
\hline
\end{tabular}

Values are represented as mean $\pm \mathrm{SD}$ of 22 subjects /group. $P$ value was significant at $<0.05$.

a: Significant difference from normal control group; b: Significant difference from obese group; c: Significant difference from type 2 DM group. ${ }^{*} \%$ change from control group. ${ }^{* *} \%$ change from non-obese type 2 DM group 
Table 2: Fasting plasma glucose, glycosylated hemoglobin, plasma insulin levels and HOMA-IR scores of participants included in the different studied groups.

\begin{tabular}{|c|c|c|c|c|}
\hline $\begin{array}{c}\text { Parameters } \\
\text { Groups }\end{array}$ & $\begin{array}{c}\text { Plasma Glucose } \\
(\mathrm{mmol} / \mathrm{L})\end{array}$ & $\begin{array}{c}\text { HbAlc } \\
\%\end{array}$ & $\begin{array}{c}\text { Plasma insulin } \\
(\mathrm{mU} / \mathrm{L})\end{array}$ & HOMA-IR \\
\hline Normal Control & $5.00 \pm 0.60$ & $5.37 \pm 0.60$ & $10.03 \pm 0.80$ & $2.20 \pm 0.50$ \\
\hline $\begin{array}{c}\text { Obese without DM } \\
* \% \text { change }\end{array}$ & $5.29 \pm 0.56$ & $5.61 \pm 0.54$ & $14.45 \pm 1.75^{\mathrm{a}}$ & $3.39 \pm 0.50^{\mathrm{a}}$ \\
Non obese T2 DM & $11.67 \pm 1.70^{\mathrm{ab}}$ & $9.05 \pm 1.17^{\mathrm{ab}}$ & $15.30 \pm 1.20^{\mathrm{a}}$ & $7.75 \pm 1.00^{\mathrm{ab}}$ \\
$* \%$ change & 133.40 & 68.53 & 52.54 & 252.27 \\
\hline Obese with T2 DM & $16.54 \pm 4.1^{\mathrm{abc}}$ & $11.09 \pm 1.90^{\mathrm{abc}}$ & $16.40 \pm 1.00^{\mathrm{ab}}$ & $12.10 \pm 1.4^{\mathrm{abc}}$ \\
$*$ change & 230.80 & 106.52 & 63.51 & 450.00 \\
$* *$ change & 41.73 & 22.54 & 7.19 & 56.13 \\
\hline
\end{tabular}

Values are represented as mean $\pm \mathrm{SD}$ of 22 subjects /group. $P$ value was significant at $<0.05$.

a: Significant difference from normal control group; b: Significant difference from obese group; c: Significant difference from type 2 DM group. ${ }^{*} \%$ change from control group. ${ }^{* *} \%$ change from non-obese type 2 DM group

Table 3: Lipid profile of participants included in the different studied groups.

\begin{tabular}{|c|c|c|c|c|c|}
\hline Parameters & $\begin{array}{c}\text { Serum TC } \\
(\mathbf{m g} \%)\end{array}$ & $\begin{array}{c}\text { Serum HDL } \\
(\mathbf{m g} \%)\end{array}$ & $\begin{array}{c}\text { Serum LDL } \\
(\mathbf{m g} \%)\end{array}$ & $\begin{array}{c}\text { Serum TG } \\
(\mathbf{m g} \%)\end{array}$ & TC / HDL \\
\hline Groups & $\begin{array}{c}186.52 \pm \\
28.97\end{array}$ & $51.08 \pm$ & $112.40 \pm$ & $104.16 \pm$ & $3.70 \pm$ \\
\hline Normal Control & 5.80 & 21.01 & 27.18 & 0.40 \\
\hline Obese without DM & $242.12 \pm$ & $43.32 \pm$ & $137.08 \pm 22.47^{\mathrm{a}}$ & $259.96 \pm$ & $5.23 \pm$ \\
\% change & $24.46^{\mathrm{a}}$ & $6.58^{\mathrm{a}}$ & 21.95 & $36.90^{\mathrm{a}}$ & $0.49^{\mathrm{a}}$ \\
\hline Non obese T2 DM & 29.81 & -15.19 & & 149.58 & 41.35 \\
\hline change & $235.60 \pm$ & $43.20 \pm$ & $155.15 \pm$ & $185.35 \pm$ & $5.50 \pm$ \\
& $30.13^{\mathrm{a}}$ & $4.36^{\mathrm{a}}$ & $26.06^{\mathrm{a}}$ & $25.97^{\mathrm{ab}}$ & $0.60^{\mathrm{a}}$ \\
\hline \% & 26.31 & -15.42 & 38.03 & 77.95 & 48.65 \\
\hline \%bese with T2 DM & $301.70 \pm$ & $34.50 \pm$ & $217.55 \pm$ & $261.00 \pm$ & $8.70 \pm$ \\
\hline
\end{tabular}

Values are represented as mean $\pm \mathrm{SD}$ of 22 subjects /group. $P$ value was significant at $<0.05$.

a: Significant difference from normal control group; b: Significant difference from obese group; c: Significant difference from type 2 DM group. ${ }^{*} \%$ change from control group. ${ }^{* *} \%$ change from non-obese type 2 DM group

Parameters of oxidative status and endothelial function were listed in Table (4): Results of oxidative status parameters revealed that in obese patients without type2 DM serum levels of MDA were significantly increased $(P<0.05)$ by $18.76 \%$ while serum TAC levels were significantly decreased $(P<0.05)$ by $12.80 \%$ as compared to the normal control subjects. Non obese type2 DM patients comparing to their respective normal controls showed the same results but with different $\%$ change values (MAD 31.14\% \& TAC -36.54\%). In addition, obese type $2 \mathrm{DM}$ patients had significantly higher $(P<0.05)$ MDA levels by $13.02 \%$ while they had significant lower $(P<0.05)$ TAC levels by $19.19 \%$ than the non-obese type $2 \mathrm{DM}$ group. 
Concerning the endothelial function parameters, the obese group of patients without type $2 \mathrm{DM}$ had significantly higher $(P<0.05)$ levels of serum VCAM-1 and sol. endoglin (\% change: 33.88 \& $17.39 \%$ respectively) than the control group. The two parameters showed the same significant changes in the non-obese type $2 \mathrm{DM}$ patients compared to the normal control ones but with higher values of \% changes (50.94 and 26.09\% respectively). Furthermore, comparing obese type 2 DM patients to the non-obese diabetic ones, serum levels of VCAM-1 and sol. endoglin were also significantly increased $(P<0.05)$ with \% changes 12.87 and $36.21 \%$ respectively.

Correlation studies (Table 5): In the non-obese type 2 $\mathrm{DM}$ and obese type $2 \mathrm{DM}$ groups of patients, positive significant correlations were found between sol. endoglin and plasma glucose (r $0.542 \& P<0.001$ and $\mathrm{r}$ $0.652 \& \quad P<0.001$ respectively); also between sol. endoglin and insulin $(\mathrm{r}=0.589 \& P<0.001$ and $\mathrm{r}=0.682$ $\& P<0.001$ respectively) and between sol. endoglin and HOMA-IR $(\mathrm{r}=0.517 \& \quad P<0.001$ and $\mathrm{r}=0.551 \&$ $P<0.001$ respectively). Sol. endoglin also showed significant positive correlations with $\mathrm{TC}$ in the obese with or without type $2 \mathrm{DM}$ groups $(\mathrm{r}=0.459 \& P<0.01$ and $\mathrm{r}=0.446 \& \quad P<0.026$ respectively) however, it showed a positive significant correlation with MDA ( $\mathrm{r}=$ $0.921 \& P<0.001)$ in the obese with type $2 \mathrm{DM}$ group only.

\section{Discussion}

Obesity plays a central role in the insulin resistance syndrome, which includes hyperinsulinemia, hypertension, hyperlipidemia, Type 2 diabetes mellitus, and an increased risk of atherosclerotic cardiovascular disease $^{\lfloor 28\rfloor}$.

This study enrolled obesity as a risk factor for cardiovascular diseases in obese without type 2 DM patients and with type $2 \mathrm{DM}$ patients and assessed the association between sol. endoglin and insulin resistance, hyperlipidemia, oxidative stress and endothelial dysfunction. The study also examined the possibility of using sol. endoglin as a predictor of future adverse cardiovascular events in obese and/or type 2 DM patients.

All participants in this study were age matched and normotensive (Table 1). Results collected from Table (2) indicated that obesity induced a degree of insulin resistance manifested from the elevated HOMA-IR scores $(54.09 \%)$. Furthermore, both of the type 2 DM groups either non obese or obese exhibited poor glycemic control and insulin resistance however, the involvement of obesity induced dramatic changes. These findings were in agreement with Rexrode et al. ${ }^{[29]}$ who reported that obesity has been strongly associated with insulin resistance in normoglycemic persons and in individuals with Type 2-diabetes and that increases the risk of cardiovascular disease in adults. Also Šindelka et al. ${ }^{[30]}$ concluded that obesity may have even greater influence on the insulin action than diabetes mellitus itself. The positive significant correlations found between sol. endoglin and plasma glucose, insulin and HOMA-IR (Table 5) supported the link between endoglin and the glycemic status in the diabetic groups. Blazques-Medela et al. ${ }^{[13]}$ reported that there was a significant correlation between sol endoglin and glycemia however with hypertension as a risk factor for cardiovascular complications in patients with type 2 DM.

Table 4: Serum malondialdehyde, total antioxidant capacity, vascular cell adhesion molecule-1 and sol. endoglin levels of participants included in the different studied groups.

\begin{tabular}{|c|c|c|c|c|}
\hline $\begin{array}{c}\text { Parameters } \\
\text { Groups }\end{array}$ & $\begin{array}{c}\text { Serum MDA } \\
(\mathbf{n m o l} / \mathbf{L})\end{array}$ & $\begin{array}{c}\text { Serum TAC } \\
(\mathbf{m m o l} / \mathbf{L})\end{array}$ & $\begin{array}{c}\text { Serum VCAM-1 } \\
(\mathbf{n g} / \mathbf{m l})\end{array}$ & $\begin{array}{c}\text { Serum Endoglin } \\
(\mathbf{p g} / \mathbf{m l})\end{array}$ \\
\hline Normal Control & $5.33 \pm 1.04$ & $1.56 \pm 0.10$ & $468.40 \pm 16.83$ & $4.60 \pm 0.71$ \\
\hline $\begin{array}{c}\text { Obese without DM } \\
\text { \% change }\end{array}$ & $6.33 \pm 0.99^{\mathrm{a}}$ & $1.22 \pm 0.09^{\mathrm{a}}$ & $627.10 \pm 37.60^{\mathrm{a}}$ & $5.40 \pm 0.69^{\mathrm{a}}$ \\
\hline $\begin{array}{c}\text { Non obese T2 DM } \\
\text { \% change }\end{array}$ & 18.76 & -12.80 & 33.88 & 17.39 \\
\hline Obese with T2 DM & $7.90 \pm 1.09^{\mathrm{abc}}$ & $0.80 \pm 0.08^{\mathrm{abc}}$ & $798.00 \pm 47.40^{\mathrm{abc}}$ & $7.90 \pm 0.78^{\mathrm{abc}}$ \\
\hline \% change & 48.22 & -48.71 & 70.36 & 71.74 \\
\hline \% change & 13.02 & -19.19 & 12.87 & $36.71^{\mathrm{a}}$ \\
\hline
\end{tabular}

Values are represented as mean $\pm \mathrm{SD}$ of 22 subjects /group. $P$ value was significant at $<0.05$.

a: Significant difference from normal control group; b: Significant difference from obese group; c: Significant difference from type 2 DM group. ${ }^{*} \%$ change from control group. ${ }^{* *} \%$ change from non-obese type 2 DM group 
Table 5: Pearson's correlation coefficient (r) between sol. endoglin and some biochemical parameters in the different studied groups.

\begin{tabular}{|c|c|c|c|c|c|c|}
\hline & & & & & \\
\hline & & Glucose & Insulin & HOMA-IR & $\begin{array}{c}\text { Total } \\
\text { cholesterol }\end{array}$ & MDA \\
\hline \multirow{2}{*}{$\begin{array}{c}\text { Obese without } \\
\text { DM }\end{array}$} & $\begin{array}{c}\text { Pearson's } \\
\text { correlation(r) }\end{array}$ & \multirow[t]{2}{*}{ N.S } & \multirow[t]{2}{*}{ N.S } & \multirow[t]{2}{*}{ N.S } & 0.446 & \multirow[t]{2}{*}{ N.S } \\
\hline & $P$ value $<$ & & & & 0.026 & \\
\hline \multirow[t]{2}{*}{ T2DM } & $\begin{array}{l}\text { Pearson's } \\
\text { correlation(r) }\end{array}$ & 0.542 & 0.589 & 0.517 & \multirow[t]{2}{*}{ N.S } & \multirow[t]{2}{*}{ N.S } \\
\hline & $P$ value $<$ & 0.001 & 0.001 & 0.001 & & \\
\hline \multirow{2}{*}{$\begin{array}{l}\text { Obese with } \\
\text { T2DM }\end{array}$} & $\begin{array}{c}\text { Pearson's } \\
\text { correlation(r) }\end{array}$ & 0.652 & 0.682 & 0.551 & 0.459 & 0.921 \\
\hline & $P$ value $<$ & 0.001 & 0.001 & 0.001 & 0.01 & 0.001 \\
\hline
\end{tabular}

Impaired lipid metabolism resulting from uncontrolled hyperglycemia has been implicated in cardiovascular complications in diabetes patients ${ }^{[31]}$.Unfavorable lipids patterns were found in the obese patients against the control subjects and in the obese type 2 DM patients against the non-obese ones (Table 3 ). These findings were manifested from the significant differences observed when comparing the various parameters of blood lipid profile in relation to TC, LDL-C, TG HDL-C levels and TC/HDL-C ratio in these groups. It was reported that dyslipidemia of obesity is commonly manifested as high plasma triglyceride levels, low HDL$\mathrm{C}$ and normal LDL-C with preponderance of small dense LDL- particles ${ }^{[32]}$ and there is a linear correlation between the degree of obesity and plasma level of LDL cholesterol and triglycerides ${ }^{[33]}$.Current results indicated that hypercholesterolemia were associated with increased levels of sol. endoglin in the obese groups as indicated from the positive significant correlations between sol. endoglin and TC in the obese groups with or without type 2 DM groups (Table 5). Recently, Beiroa et al. ${ }^{[14]}$ reported for first time that heterozygous endoglin deficiency in mice decreases high fat dietinduced hepatic triglyceride content and insulin levels. The overall findings of those authors indicated that endoglin is a potentially important physiological mediator of insulin levels and hepatic lipid metabolism. Accumulating evidence suggested a close relationship between hyperlipidemia and oxidative stress in obese patients ${ }^{[34]}$. In the present study (Table 4) all the studied groups exhibited certain degrees of oxidative stress compared to the normal control group manifested from the elevation in levels MDA and the reduction in the levels of TAC. However, from the $\%$ change values it was severely presented in the obese diabetic group of patients compared to the control group (MDA $48.22 \%$ and TAC $-48.71 \%$ respectively). This could be explained on the bases that obesity is associated with increased oxygen consumption, cell injury/inflammation, increased fat deposition, and compromised antioxidant defense ${ }^{[35]}$ and that the greater the obesity, the greater demand on antioxidant enzymes to combat free-radical damage, hence antioxidant enzymes become depleted [36] Additionally, the increased superoxide production from fatty acids in mitochondria of the endothelial cells directly inactivates 2 critical anti-atherosclerotic enzymes, endothelial nitric oxide synthase and prostacyclin synthase causing defective angiogenesis ${ }^{[37]}$. Furthermore, in the diabetic condition, oxidative stress impairs glucose uptake in muscle and adipocytes ${ }^{[38]}$ and affected insulin secretion from pancreatic $B$ cells thus causing abnormalities in the secretion and action of insulin ${ }^{[39]}$. In the present results the positive significant correlations between sol. endoglin and MDA in the obese type 2 DM group (Table 5) indicating possible association between sol. endoglin and oxidative stress in this group.

Endothelial dysfunction represents an early phase of vascular changes that eventually lead to atherosclerosis with all its unfavorable complications and the damaged endothelium presents a range of adhesion molecules to the arterial lumen ${ }^{[40]}$. In the current study the levels of VCAM-1was elevated ascending from the obese group without type $2 \mathrm{DM}(33.88 \%)$ to the obese group with type 2 DM (70.36 \%). Previous study of Bošanská et al. [41] declared that circulating adhesion molecules like VCAM-1 in patients with obesity were elevated and that this effect may play an important role in the development of endothelial dysfunction-/atherosclerosis. Further studies reported that poor glycemic control together with increased glucose levels may be responsible for significant higher levels of VCAM-1 in diabetic patients [42'43].

From the current results the elevations in the levels of 
sol. endoglin were parallel to that of VCAM-1 levels in the sera of obese patients without type 2 DM against the controls and in the sera of obese type $2 \mathrm{DM}$ patients against the non-obese ones (Table 4). This indicated an association between sol. endoglin and endothelial dysfunction which was found to be increased when obesity enrolled as a risk factor of cardiovascular alterations in these groups. The results of Kurki $\boldsymbol{e t}$ al. ${ }^{[44]}$ in mice indicated that obesity was associated with increased expressions of angiogenesis-related proteins among which were sol. endoglin. Recently, it was reported that in the normal state, L-endoglin modulated the TGF- $\beta$ response but upon senescence of endothelial cells, S-endoglin is up-regulated, interacting with the TGF- $\beta$ receptor complex containing ALK1 and ALK5 ${ }^{[45,46]}$. As a consequence of this interaction, S-endoglin up-regulate plasminogen activator inhibitor type1 (PAI1)/extra-cellular matrix (ECM) synthesis which may lead to increased fibrosis; down-regulate inhibitor of DNA binding 1 (Id1) which associated with decreased angiogenesis and down-regulate endothelia nitric oxide synthase and up-regulate cyclooxygenase- 2 which are involved in endothelial dysfunction and impaired vascular relaxation ${ }^{[47,48]}$. Also, endoglin regulates the half-life and activity of eNOS thus S-endoglin allows a switch that triggers the cardiovascular pathology ${ }^{[49]}$. In addition sol. endoglin amplifies the vascular damage mediated by vascular endothelial growth factor1 (VEGF-1) ${ }^{[50]}$.

Conclusion: It can be concluded that sol. endoglin is associated with poor glycemic control, impairment in lipid metabolism and oxidative stress. Additionally, sol. endoglin seems to be associated with impaired endothelial function which is a major characteristic of patients with obesity and /or diabetes. The results were relevant enough to establish the relative strength of prediction of cardiovascular risk according to the endoglin level presented by the patient.

\section{Acknowledgement}

The authors would like to acknowledge the members of Internal Medicine Department in National Institute of Diabetes and Endocrinology (NIDE), Cairo, Egypt for their help in selection and clinical diagnosis of patients.

\section{References}

1) Cade WT (2008). Diabetes-Related Microvascular and Macrovascular Diseases in the Physical Therapy Setting. Phys Ther. 88 (11): 1322-1335.

2) Taddei S, Ghiadoni L, Virdis A, Versari D and Salvetti A (2003). Mechanisms of endothelial dysfunction: clinical significance and preventive non pharmacological therapeutic strategies. Curr Pharm Des, 9: 2385-2402.

3) Versari D, Daghini E, Virdis A, Ghiadoni L and Taddei S (2009). Endothelial dysfunction as a target for prevention of cardiovascular disease. Diabetes Care, 32(2):S314-S321.

4) Vasan R.S. (2006). Biomarkers of Cardiovascular
Disease: Molecular Basis and Practical Considerations. Circulation, 113: 2335-2362.

5) Conley BA, Koleva R, Smith JD, Kacer D and Zhang D (2004): Endoglin controls cell migration and composition of focal adhesions: function of the cytosolic domain. J Biol Chem, 279(26):2744027449.

6) Velasco S, Alvarez-Munoz P, Pericacho M, Dijke P, Bernabeu C,Lopez-Novoa JM, and RodriguezBarbero A (2008)."L- and S-endoglin differentially modulate TGF beta1 signaling mediated by ALK1 and ALK5 in L6E9 myoblasts." J Cell Sci, 15 (121(Pt 6)): 913-919.

7) Lopez-Novoa JM and Bernabeu C (2010). The physiological role of endoglin in the cardiovascular system. Am J Physiol Heart Circ Physiol, 299(4): H 959-974.

8) Blanco FJ, Santibanez JF, Guerrero-Esteo M, Langa C, Vary CP and Bernabeu C (2005). Interaction and functional interplay between endoglin and ALK-1, two components of the endothelial transforming growth factor beta receptor complex. $J$ Cell Physiol, 204: 574-584.

9) Mahmoud M, Borthwick GM, Hislop AA and Arthur HM (2009). Endoglin and activin receptorlike-kinase 1 are co-expressed in the distal vessels of the lung: implications for two familial vascular dysplasias, HHT and PAH. Lab Invest, 89: 15-25.

10) Lebrin F, Goumans MJ, Jonker L, et al (2004). Endoglin promotes endothelial cell Proliferation and TGF-beta/ALK1 signal transduction. EMBO Journal, 23(20): 4018-4028.

11) Nachtigal $P$, Zemankova Vecerova $L$, Rathouska J, Strasky $Z$ (2012). The role of endoglin in atherosclerosis. Atherosclerosis, 224(1):4-11.

12) El-Naggar GF, El-Srogy HA (2012). Is there a relationship between plasma levels of soluble endoglin and cardiovascular alterations in patients with hypertension and diabetes mellitus? Journal of American Science.8 (9):1124-1131.

13) Blazques-Medela A, Garcia-Ortiz L, GomezMarcos MA, Reco-Rodriques JI, Sanchez Rodrigues A, Lopaez-Nova JM and Martinzsalgado C (2010). Increased plasma soluble endoglin levels as an indicator of cardiovascular alterations in hypertensive and diabetic patients. BMC Medicine, 8(80):1-12.

14) Beiroa $D$, Romero-Pico' A, Langa $C$, Bernabeu $C$, Lo' $^{\prime}$ pez M, Lo' pez-Novoa JM, Nogueiras $R$, Die'guez C (2013). Heterozygous Deficiency of Endoglin Decreases Insulin and Hepatic Triglyceride Levels during High Fat Diet. PLOS ONE, 8 (1) :1-11.

15) Giugliano D, Ceriello A and Esposito $K$ (2008). Glucose metabolism and hyperglycemia. Am J Clin Nutr, 87(suppl):217S-22S.

16) Trinder $P$ (1969). Determination of glucose in blood using glucose oxidase with an alternative oxygen acceptor. Ann Clin biochem, 6: 24-27. 
17) Grey V, Perlas $M$ and Aebi C. (1996). Immunoturbidimetric method for determination hemoglobin A1c., Clin. Chem. 42(12): 2046-2047.

18) Flier J S, Kahn C R and Roth J (1979): Receptors anti-receptor antibodies and mechanisms of insulin resistance. N Engl. J. Med., 300 (8) 413-419.

19) Matthews DR, Hosker JP, Rudenski AS, Naylor BA, Treacher DF, Turner RC (1985). "Homeostasis model assessment: insulin resistance and beta-cell function from fasting plasma glucose and insulin concentrations in man." Diabetologia 28 (7): 412-419.

20) Allain CC, Poon TS, Chan CS Richamand W and Fu PC (1974). Enzymatic determination of total serum cholesterol. Clin Chem, 20: 470.

21) Lopes-Virella MF, Stone PG, Ellis $S$ and Colwell JA (1977). Cholesterol determination in highdensity lipoproteins separated by three different methods. Clin Chem, 23 (5):882-884.

22) Fassati P and Prencipe $L$ (1982): Determination of serum triglycerides. Clin Chem, 19: 2077-2080.

23) Friedewald WT, Levy RI and Fredrickson DS (1972). Estimation of the concentration of lowdensity lipoprotein cholesterol in plasma, without use of the preparative ultracentrifuge. Clin Chem, 18: 499-502.

24) Wilson, PW, Garrison RJ, Castelli WP, Feinleib $M$ and Kannel WB (1980). Prevalence of coronary heart disease in the Framingham off spring study: Role of lipoprotein cholesterols. Am J Cardiol. 46: 649-654.

25) Uchiyama $M$ and Mihara $M \quad$ (1978). Determination of malonialdehyde precursor in tissues by thiobarbituric acid test. Anal Biochem. 86: 271-278.

26) Koracevic D, Koracevic D, Jordjevic V, Andrejevic S and Cosic V (2001). Method for the measurement of antioxidant activity in human fluids. J Clin Pathol. 54: 356-361.

27) Abdalla SA, Pece-Barbara N, Vera S, Tapia E, Paez E, Bernabeu $C$ and Letarte $M$ (2000). Analysis of ALK-1 and endoglin in newborns from families with hereditary hemorrhagic telangiectasia type 2. Hum Molec Genet, 9: 1227-1237.

28) Grundy SM, Brewer HB Jr, Cleeman JI, Sidney C, Smith SC Jr and Lenfant C (2004). Definition of Metabolic Syndrome: Report of the National Heart, Lung, and Blood. Circulation, 109: 433-438.

29) Rexrode K.M., Manson J.E. and Hennekens C.H. (1996). Obesity and cardiovascular disease. Curr Opin Cardiol; 11: 490-495.

30) Šindelka G, Škrha J, Prázný $M$ and Haas $T$ (2002). Association of Obesity, Diabetes, Serum Lipids and Blood Pressure Regulates Insulin Action. Physiol Res, 51: 85-91.

31) Gregg EW, Cheng YJ, Cadwell Bl, Imperatore G, Williams DE et al. (2005). Secular trends in cardiovascular disease risk factors according to body mass index in US adults. JAMA, 293: 1868-
1874.

32) Mooradian AD, Haas MJ, Wehmeier KR, and Wong MCW (2008). Obesity-related Changes in High-density Lipoprotein Metabolism. Obesity, 16: $1152-1160$.

33) Szczygielska A, Widomska S, Jaraszkiewicz M, Knera $P$ and Muc K (2003). Blood lipids profile in obese or overweight patients. Ann Univ Mariae Curie Sklodowska [Med], 58(2):343-349.

34) Savini I, Catani MV, vangelista DE, Gasperi V and Avigliano L (2013). "Obesity-associated oxidative stress: strategies finalized to improve redox state," International Journal of Molecular Sciences, 14(5): 10497-10538.

35) Sankhla M, Sharma TK, Mathur K, Rathor JS and Butolia V (2010). Relationship of oxidative stress with obesity and its role in obesity induced metabolic syndrome. Clin lab, 58(56):385-392.

36) Dambal1 SS and Kumari SN (2012). Evaluation of lipid peroxidation and total antioxidant status in human obesity. International Journal of Institutional Pharmacy and Life Sciences, 2(3):62-68.

37) Giacco $F$ and Brownlee $M$ (2010). Oxidative Stress and Diabetic Complications. Circ Res, 107:10581070.

38) Maddux BA, See W, Lawrence JC, et al. (2001). Protection against oxidative stress-induced insulin resistance in rat L6 muscle cells by mircomolar concentrations of alpha-lipoic acid. Diabetes, 50: 404-410.

39) Kawahito S, Kitahata $H$ and Oshita $S$ (2009). Problems associated with glucose toxicity: role of hyperglycemia-induced oxidative stress. World J. gastro enterol, 7(33):4137-4142.

40) Blankenberg S, Barbaux $S$ and Tiret $L$ (2003). Adhesion molecules and atherosclerosis. Atherosclerosis, 170: 191-203.

41) Bošanská L, Michalský D, Lacinová Z, Dostálová I, Bártlová M, Haluzíková D, et al. (2010).The Influence of Obesity and Different Fat Depots on Adipose Tissue Gene Expression and Protein Levels of Cell Adhesion Molecules. Physiol. Res., 59: 7988.

42) Pham MN, Hawa MI, Roden M, Schernthaner G, Pozzilli P, Buzzetti R, et al. (2012). The Action LADA Study Group. Increased serum concentrations of adhesion molecules but not of chemokines in patients with Type 2 diabetes compared with patients with Type 1 diabetes and latent autoimmune diabetes in adult age: Action LADA 5. Diabet. Med., 29:470478.

43) Matsumoto K, Sera Y, Nakamura H, Ueki Y and Miyake S (2002). Serum concentrations of soluble adhesion molecules are related to degree of hyperglycemia and insulin resistance in patients with type 2 diabetes mellitus. Diabetes Res Clin .Prac., 55:131-138.

44) Kurki E, Shi J, Martonen E, Finckenberg $P$ and Mervaala E (2012). Distinct effects of calorie 
restriction on adipose tissue cytokine and angiogenesis profiles in obese and lean mice. Nutrition \& Metabolism, 9:64.

45) Kapur NK, Kevin J, Morine KJ and Letarte $M$ (2013). Endoglin: a critical mediator of cardiovascular health. Vascular Health and Risk Management, 9: 195-206.

46) Blanco FJ, Grande MT, Langa C, Oujo B, Soraya Velasco, Rodriguez-Barbero A, et al (2008): S-Endoglin Expression Is Induced in Senescent Endothelial Cells and Contributes to Vascular Pathology. Circulation Research, 103:1383-1392.

47) Jerkic M, Rivas-Elena JV, Santibanez JF, Prieto $M$ and Rodriguez- Barbero A (2006). Endoglin regulates cyclooxygenase-2 expression and activity. Circ Res, 99(3):248-256
48) Botella LM, Sanchez-Elsner T, Sanz-Rodriguez F, Kojima S, Shimada J, Guerrero-Esteo M et al. (2002). Transcriptional activation of endoglin and trans-forming growth factor-beta signaling components by cooperative interaction between $\mathrm{Sp} 1$ and KLF6: their potential role in the response to vascular injury. Blood, 100(12):4001-4010.

49) Toporsian M, Gros R, Kabir MG, Vera S, Govindaraju K, Eidelman DH, Husain M, Letarte M (2005). A role for endoglin in coupling eNOS activity and regulating vascular tone revealed in hereditary hemorrhagic telangiectasia. Circ. Res. 96: 684-692.

50) Barleon B, Reusch $P$, Totzke $F$, Herzog $C$ and Keck C (2001). Soluble VEGFR-1 secreted by endothelial cells and monocytes is present in human serum and plasma from healthy donors. Angiogenesis, 4(2): 143-154 